\title{
Study Day of Tumor Identification
}

National Cancer Institute

\section{Source}

National Cancer Institute. Study Day of Tumor Identification. NCI Thesaurus. Code C117431.

The study day that a tumor identification assessment is performed. 